\title{
Determination of the chemical composition of the residual powder in order to identify the source of release
}

\author{
Sonia Niculina Șuvar ${ }^{1 *}$, Maria Prodan $^{1}$, Andrei Szollosi-Moța ${ }^{1}$, Irina Nălboc ${ }^{1}$, and Aurelian \\ Nicola $^{2}$ \\ ${ }^{1}$ National Institute for Research and Development in Mine Safety and Protection to Explosion - \\ INSEMEX, Department for Safety of Mineral Resources, 32-34 Gen. Vasile Milea Street, Petrosani, \\ Romania \\ ${ }^{2}$ University of Petrosani, Department of Mechanical, Industrial and Transport Engineering, 20 \\ University Street, Petrosani, Romania
}

\begin{abstract}
Particles in suspension come mainly from pollutant emissions generated by industry, traffic, home heating, etc. Due to these particles, various diseases can occur, such as lung cancer, asthma, cardiovascular diseases. An important problem is represented by the particles with an aerodynamic diameter of less than 10 micrometers, which pass through the nose and throat and enter the alveoli of the lungs causing inflammation and intoxication. This paper aimed to establish the chemical composition of residual powders in a production hall from the automotive industry, to identify the source of release. For this, the infrared spectrometry (FTIR) method, the inductively coupled plasma optical emission spectrometry (ICP-OES) method, and the x-ray spectrometry (XRF) method were used. Two samples of dust from different locations of the production hall were analyzed, as well as a substance used in the process, to determine whether the dust came from its use. A series of safety data sheets for substances used in the technological process was also analyzed. The results obtained from the qualitative and quantitative determinations were evaluated considering the chemical composition of all substances involved, leading to the identification of the residual dust release source.
\end{abstract}

\section{Introduction}

In order to ensure the protection of human health, knowing the aspects regarding the environmental factors is an essential activity. The presence of harmful agents, their action on the human body, the required doses, their identification, and effective measurement, are realities that modern society must constantly face.

Suspended powders are small fragments of solids or liquids that can float in the air. If they are small enough in diameter to maintain stability in the air or any other gas, they may form an aerosol. Solid particles can be lifeless (dust, smoke) or alive (microorganisms),

\footnotetext{
* Corresponding author: sonia.suvar@insemex.ro
} 
while liquid particles can take the form of vapors or mists. The diameter of the suspended particles can vary from $0.005 \mu \mathrm{m}$ (small particles) to $100 \mu \mathrm{m}$. Larger and even visible powders, with diameters up to $1000 \mu \mathrm{m}$, due to their weight, tend to deposit very quickly. Although they can also cause irritation to the eyes, nose, or throat, these particles are not small enough to reach the lungs. Breathable particles are those located in the range of 0.005 $\mu \mathrm{m}-10 \mu \mathrm{m}$, but only those in the range $0.1-10 \mu \mathrm{m}$ are of increased interest because particles with a diameter smaller than $0.1 \mu \mathrm{m}$ can be easily expired [1].

Medium particles, with diameters between 1 and $100 \mu \mathrm{m}$ (pollen, large bacteria, coal dust, the dust of industrial origin, particles resulting from cutting, grinding or welding, etc.), are deposited slowly and present the greatest health risk, being able to travel through the nose and throat and penetrate the regions responsible for the exchange of gas in the lungs, where inflammation and poisoning can be deposited or caused.

Small particles, less than $1 \mu \mathrm{m}$, also pose a serious health risk. This category may include viruses, small bacteria, emissions, and dust from the metallurgical industry, respectively paint pigments. These particles can be removed from the atmosphere, by water or rain.

Suspended particles come mainly from anthropogenic sources - from pollutant emissions generated by industry, traffic (incomplete combustion, dust produced by tires), home heating sources, etc. Natural sources, such as volcanic eruptions, rock erosion, pollen dispersal, or sandstorms, contribute to a lesser extent to the generation of these complex mixtures. They can also result from the condensation of various volatile elements in the atmosphere and the formation of very small particles or by their absorption on the surface of some already formed. Heavy metals in suspended dust are emitted as a result of various combustion processes and industrial activities, they can be included or attached to the emitted dust particles, they can be deposited on the ground or in surface waters, accumulating both in the soil and in sediment. They are toxic and can affect many functions of the body, causing long-term effects through their ability to accumulate in tissues.

Exposure to these particles can lead to various serious conditions: lung cancer, asthma, cardiovascular diseases, etc. Dust pollution worsens the symptoms of asthma, coughing, chest pain, and difficulty breathing. Long-term exposure to a low concentration of dust can cause cancer and premature death [2].

We can therefore conclude that there is a correlation between the size of the suspended particles and their potential to cause effects.

Suspended particles are characterized by their complex structures and their changes due to flow, which are called flow-induced structures. Flow-induced structures in complex fluids lead to complicated flow behavior and characteristic rheological properties.

The dust composition is extremely variable and can be associated with the following components: sulfur dioxide, carbon monoxide, nitrogen oxides, and residues of hydrocarbon combustion. Heavy metals in particulate matter are emitted as a result of various combustion processes and industrial activities, they can be included or attached to the emitted dust particles, they can be deposited on the ground or in surface waters, accumulating both in the soil as well as in sediment, they are toxic and can affect many functions of the body, can have long-term effects through their ability to accumulate in tissues.

The industrial sector has been the subject of much research in this area, as industrial activities present a risk of permanent contamination for workers and the population in the surrounding areas $[3,4]$. The concentration of suspended particles and their metal content directly reflects the level of air pollution in the analyzed environment [5].

To date, the rapid monitoring, identification, differentiation, and quantification of these powders in the field have not been carried out satisfactorily, largely due to conventional analytical techniques requiring laboratory-specific environments, the application of 
complex methods, and complex procedures. sampling and preparation, etc. In addition, the quantitative analysis is partially limited by the effects induced by the particle size, as a factor of uncertainty [6-8].

Chemical analysis of suspended powders is performed by taking samples from the field, using particle filters, and analyzing these samples in specialized laboratories. The chemical composition of these particles can be determined by various analytical methods, such as mass spectrometry, atomic absorption spectroscopy, x-ray fluorescence, or by the method of Fourier transform infrared spectroscopy (FTIR) [9].

Infrared spectroscopy can be used to characterize organic and inorganic species present in suspended particles or aerosols. By this method, organic substances, sulfates, nitrates, ammonium, etc. can be detected. [10,11].

This paper presents some results of research elaborated in order to establish the chemical composition of some residual powders from a production hall in the automotive industry, to identify the source of release. Two dust samples, collected from different locations inside the production hall, and one liquid sample were analyzed using a series of analytical methods described above (the infrared spectrometry - FTIR, the inductively coupled plasma optical emission spectrometry - ICP-OES, and the x-ray spectrometry $\mathrm{XRF}$ ), to determine the possibility of their generation, following the use of a certain substance in the technological process.

By performing qualitative and quantitative determinations, in terms of chemical composition of the analyzed substances, and by consulting the relevant technical information and safety data sheets for the technological processes, provided by the applicant, the aim was to identify the source of residual dust release.

\section{Materials and methods}

The determination of the chemical composition of the residual powders to identify the source of release was performed for three samples: two of these samples were in the form of powder (Kefel powder - Sample 1 and injection powder - Sample 2) and one in the form of a liquid (Molykote white liquid - Sample 3).

\subsection{Instrumentation}

The samples were analyzed using Nicolet IS 50 FTIR Spectrometer with ATR module included, Perkin Elmer ICP-OES, HITACHI XMET 8000 GEO Expert.

Using the FTIR method with the ATR module and the X-ray spectrometry method, the two dust samples were analyzed directly on samples. The liquid sample was subjected to a drying process, the analysis being performed on the dust obtained after drying, by the FTIR-ATR method. Due to the identification of the silicon dioxide peak, the three samples were analyzed for metal content by X-ray spectrometry to determine the approximate silicon dioxide content. FTIR measurements were performed using the Nicolet IS 50 FTIR spectrometer with ATR mode included (Figure 1). The Hitachi X-MET8000 Geo portable XRF spectrometer was used for X-ray spectrometry analysis (Figure 2).

To determine metal concentrations: Cadmium, Cobalt, Chromium, Copper, Iron, Manganese, Molybdenum, Nickel, Lead, Zinc, Beryllium, Bismuth, Arsenium, Calcium, Lithium, Magnesium, Sodium, Strontium, Antimony, Titanium, Vanadium, Selenium Tellurium, from liquid and solid samples with the help of the digester, the method of inductively coupled plasma optical emission spectrometry (ICP-OES) is used, respectively the Perkin Elmer ICP-OES equipment (Figure 3). The principle of the method is the measurement of atomic emission by optical spectrometry. Inductively coupled plasma mass spectrometry uses liquid samples which, after the preparation process (digestion based on 
the use of low-pressure vessels and the microwave oven, validated for the three samples) are transformed into aerosols and introduced into the plasma. The substance of interest (being or passed) in the liquid state is nebulized (transformed into aerosols) and the resulting aerosol is carried by a gas stream (Argon) to the plasma torch.
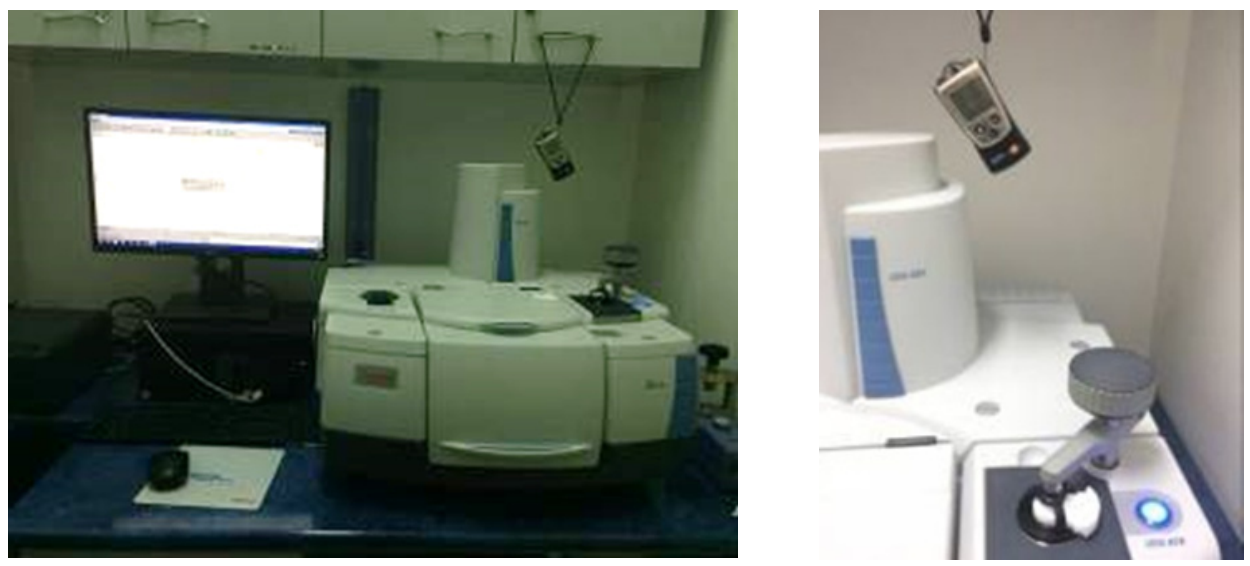

Fig.1. Nicolet iS 50 FT-IR Spectrometer, with Built-in mid- and far-IR capable diamond ATR.

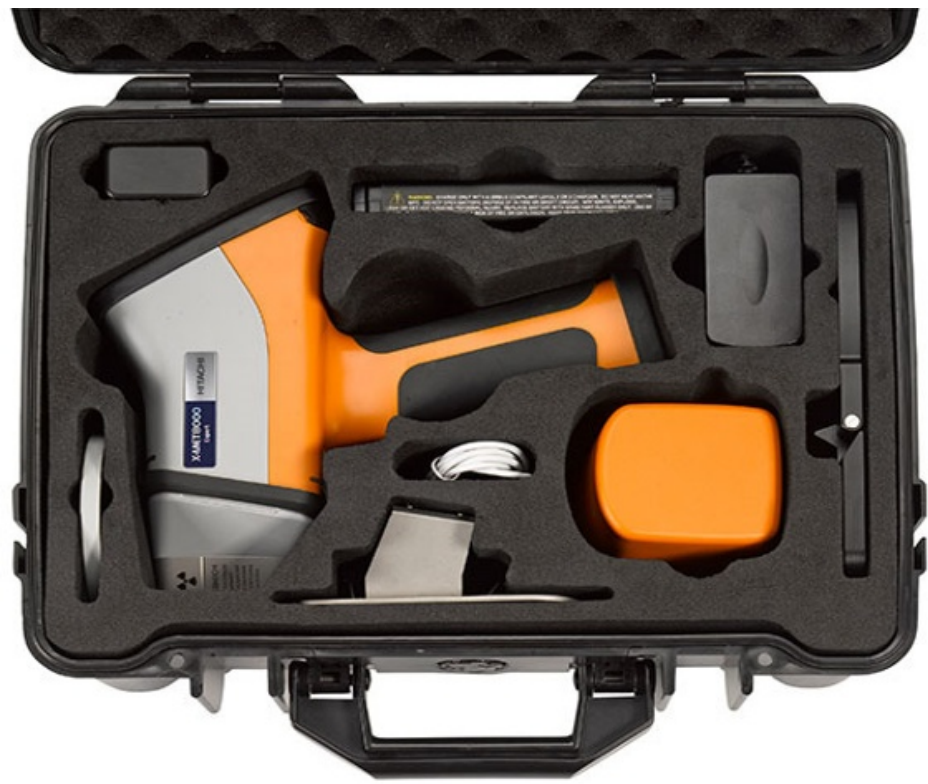

Fig. 2. Portable X-ray Fluorescence Analyzer Hitachi X-MET8000 Geo.

The experimental data obtained were evaluated using OMNIC software (Thermo Nicolet Corporation). 


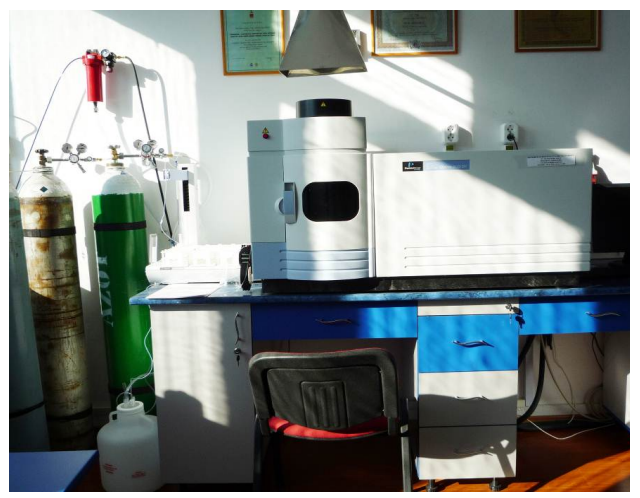

a.

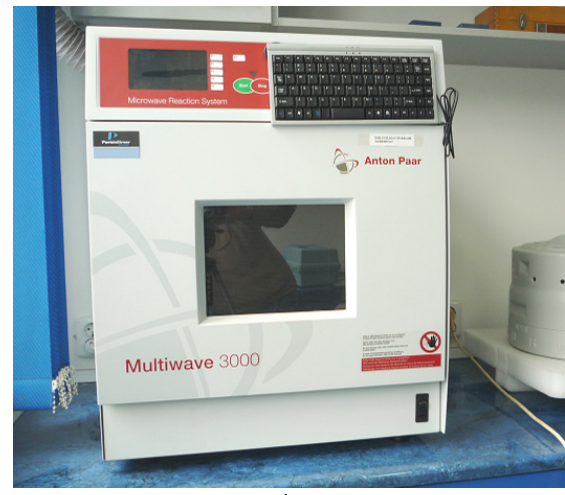

b.

Fig. 3. Inductively coupled plasma optical emission spectrometer ICP-OES Perkin Elmer (a), Microwave oven for solid sample digestion (b).

\subsection{Sample analysis}

For the evaluation of the chemical composition were used: the method of infrared spectrometry in the range $4000-400 \mathrm{~cm}^{-1}$, the method of optical emission spectrometry with inductively coupled plasma, and the method of x-ray spectrometry.

Infrared absorption spectra were recorded at a resolution of $4 \mathrm{~cm}^{-1}$ using the attenuated total reflectance (ATR) analysis technique - total reflection attenuation and transmission, as follows:

- attenuation of the total reflection, performed directly on the samples of vliss material;

- transmission, by analyzing the mixture of volatile compounds collected with the gas cell.

A number of 32 scans were performed for each spectrum.

\section{Results and discussions}

In the analysis of sample 1 and sample 2, similar IR spectra were obtained, which suggests that the two powders come from the same source (Figure 4). A characteristic peak for silicon dioxide at $2920 \mathrm{~cm}^{-1}$ was identified.

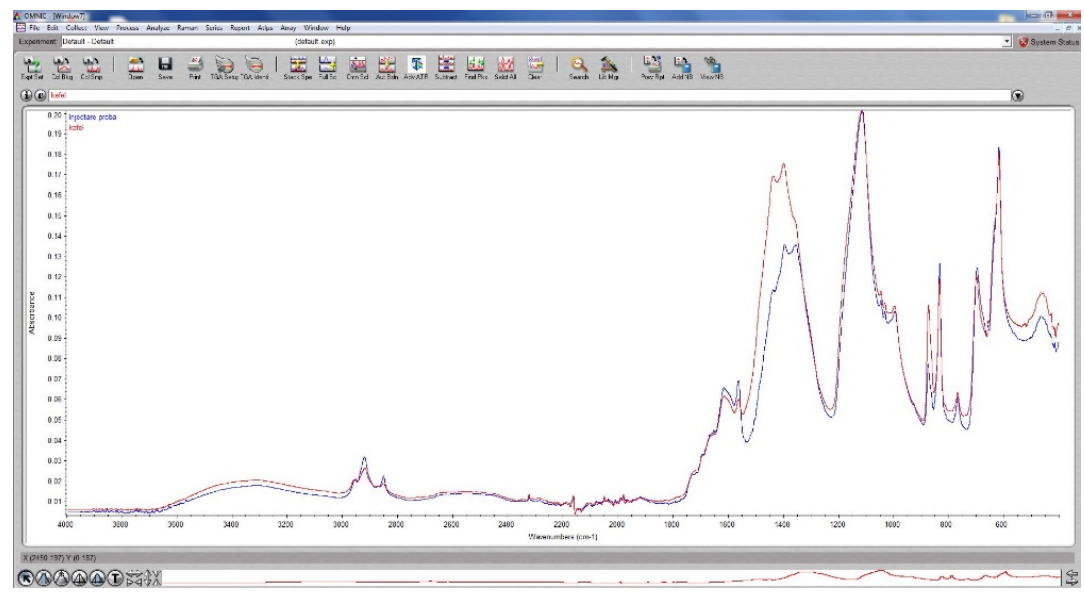

Fig. 4. IR spectrum of sample 1 and sample 2 . 
By comparing the IR spectra with the database, a probability (matching) of the spectrum with that of the cement was obtained, probably due to the high concentration of silicon dioxide in the analyzed sample.

At the analysis of the white liquid, no similarities or common peaks were identified for the three analyzed substances, so it can be said that the two powders cannot come from the use of the white liquid (Figure 5).

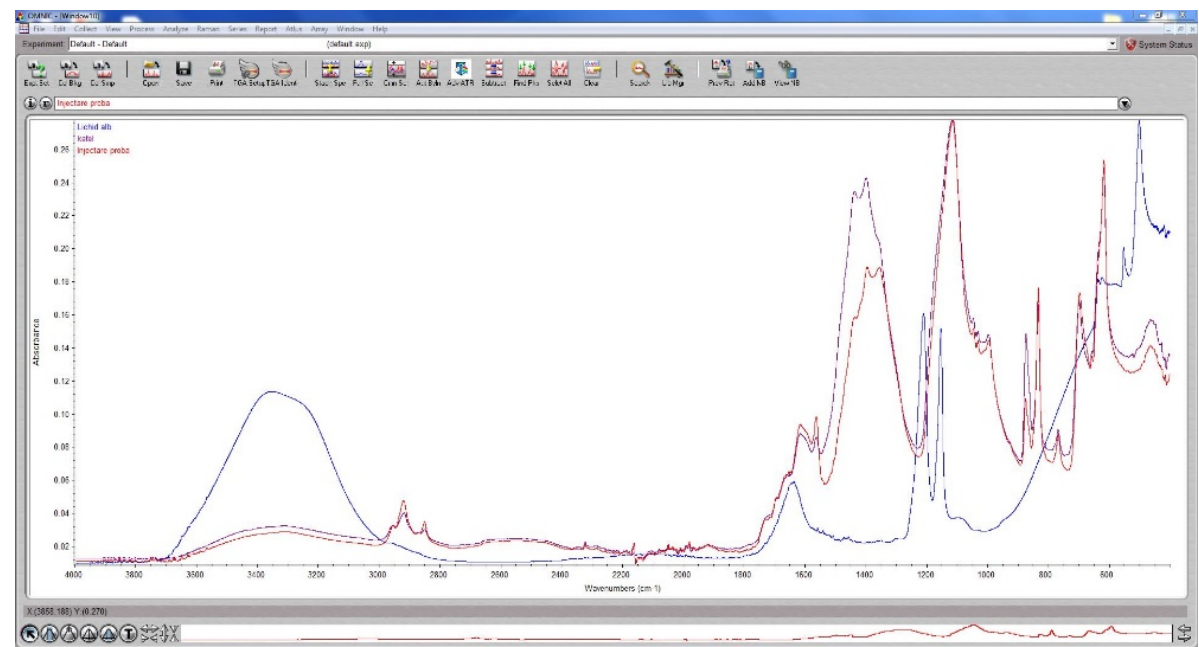

Fig. 5. IR spectrum of sample 1, sample 2 and sample 3 .

By comparing the IR spectrum with the database, a spectrum match of $90 \%$ was obtained with that of polytetrafluoroethylene-PTFE lubricants (Figure 6).

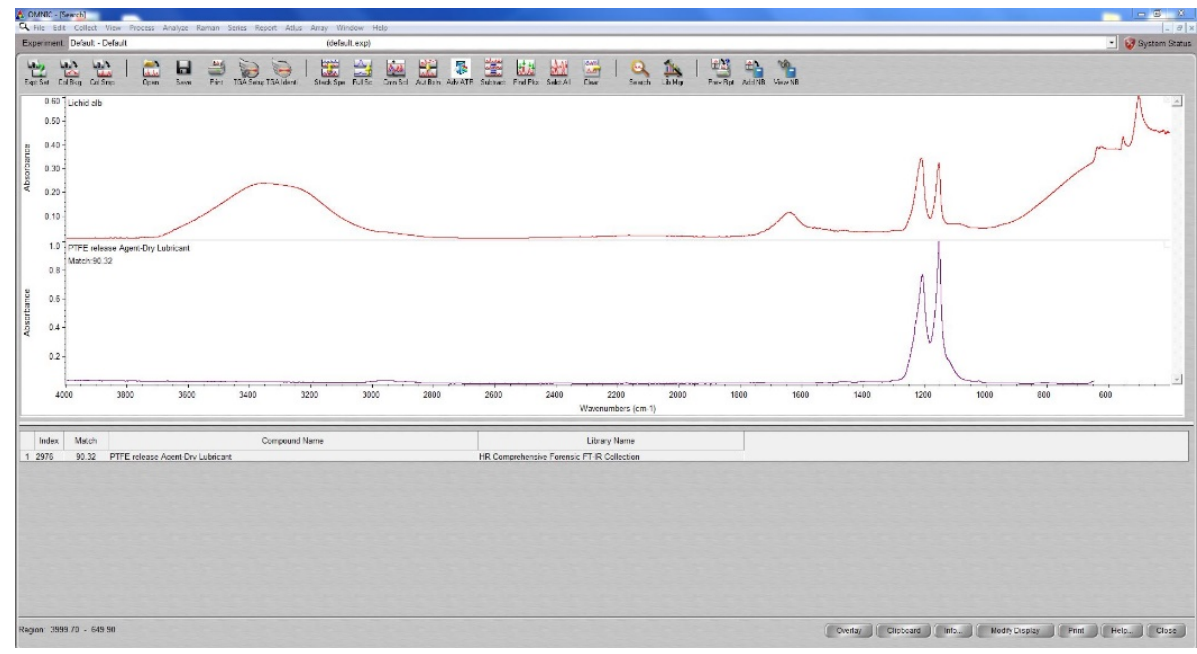

Fig. 6. Sample 3 IR spectrum.

Given the identification of the peak for silicon dioxide, the samples were analyzed from the point of view of metal content by two methods, namely X-ray spectrometry to determine the approximate content of silicon dioxide and the determination of metals by optical emission spectrometry with inductively coupled plasma. 
The results obtained suggest that the resulting powders come from the use of ULTimod 01 - Precoating powder. Taking into account the low concentrations of metals identified in the white liquid, this also excludes the possibility that the two powders come from its use.

Table 1 shows the concentration of the main metals identified in the three samples analyzed.

Table 2 shows the oxide concentrations identified in sample 1 and sample 2.

Table 1. Concentrations of metals identified in the three samples.

\begin{tabular}{|l|c|c|c|}
\hline Analyzed indicator & Sample 1 & Sample 2 & Sample 3 \\
\hline $\mathrm{SiO}_{2}$ & $11.20 \%$ & $12.00 \%$ & - \\
\hline $\mathrm{Calcium}$ & $4.90 \%$ & $2.91 \%$ & $0.0003 \%$ \\
\hline Iron & $1.06 \%$ & $1.38 \%$ & $\begin{array}{c}0.000045 \\
\%\end{array}$ \\
\hline Magnesium & $0.48 \%$ & $0.34 \%$ & $0.0006 \%$ \\
\hline Titanium & $0.02 \%$ & $0.02 \%$ & - \\
\hline Aluminum & $0.20 \%$ & $0.21 \%$ & $0.0003 \%$ \\
\hline
\end{tabular}

Table 2. Concentrations of oxides identified in sample 1 and sample 2.

\begin{tabular}{|l|c|c|}
\hline $\begin{array}{l}\text { Analyzed/calculated indicator } \\
\text { Oxide concentration }\end{array}$ & Sample 1 & Sample 2 \\
\hline Lime & $6.85 \%$ & $4.08 \%$ \\
\hline Iron oxide & $3.034 \%$ & $3.966 \%$ \\
\hline Magnesium Oxide & $0.799 \%$ & $0.566 \%$ \\
\hline Titanium oxide & $0.036 \%$ & $0.036 \%$ \\
\hline Aluminum Oxide & $0.75 \%$ & $0.81 \%$ \\
\hline
\end{tabular}

\section{Conclusions}

Following the analyzes, the following conclusions can be drawn:

- The use of the three analytical techniques (Fourier transform infrared spectrometry technique, X-ray spectrometry method, and inductively coupled plasma optical emission spectrometry method), provided a versatile tool for identifying and quantifying their various metals and oxides, from samples with complex structure analyzed.

- The two powders analyzed, sample 1 and sample 2, come from the same source, according to the characteristic infrared spectra.

- In the analysis of the white liquid (sample 3) no similarities or common peaks were identified for the three substances analyzed, so it can be said that the two powders cannot come from its use. By comparing the IR spectrum with the database, a spectrum match of $90 \%$ was obtained with that of polytetrafluoroethylene-based lubricants - PTFE).

- Evaluating the results obtained from the analyzes and the technical datasheets of the products used, the first two powder samples represent micronic powders (with deposition in time) resulting from the use of the compound ULTimod 01 - Precoating powder.

\section{References}

1. W. Kirch, Suspended Particles, Encyclopedia of Public Health (Springer, Netherlands, 2008)

2. AirQuality - National Network for Air Quality Monitoring (in Romanian). Available on https://www.calitateaer.ro/public/assessment-page/pollutants-page/pulbere-suspensie-

page/? locale $=$ ro 
3. J. K. Nagar, A. B. Akolkar, and R. Kumar, Int.J. of Env. Sc. 5 (2), 447-463 (2014)

4. N. Arshad, Z. Hamzah, A. K. Wood, A. Saat, and M. Alias, AIP Conf. Proc. 1659, 05008 (2015)

5. R. M. Harrison, and M. Jones, Science of the Total Environment 168 (3), 195-214 (1995)

6. R. Stach, T. Barone, E. Cauda, P. Krebs, B. Pejcic, S. Daboss, and B. Mizaikoff, Analytical and Bioanalytical Chemistry 412, 3499-3508 (2020)

7. R Bhaskar, J. Li, and L. Xu, Am Ind Hyg Assoc J. 55, 605-509 (1994)

8. C. M. Muller, B. Pejcic, L. Esteban, C. D. Piane, M. Raven, and B. Mizaikoff, Sci Rep. 4, 6764 (2014)

9. S. Simones Amaral, J. Andrade de Carvalho, M.A. Martins Costa, and C. Pinheiro, Atmosphere 6, 1327-1345 (2015)

10. D.T. Allen, E.J. Palen, M.I. Haimov, S.V. Hering, and J.R. Young, Aer. Sc.\& Tech., 21 (4), 325342 (1994)

11. J. Núñez, Y. Wang, S. Bäumer and A. Boersma, Sensors 20, 4193 (2020) 